\title{
Commentary: Hernia, Mesh, and Topical Antibiotics, Especially Gentamycin: Seeking the Evidence for the Perfect Outcome...
}

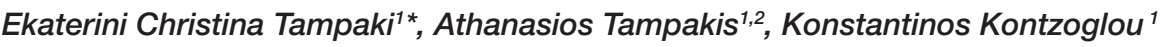
and Gregory Kouraklis ${ }^{1}$
\end{abstract}

${ }^{1}$ Second Department of Propaedeutic Surgery, Laiko General Hospital, School of Medicine, National and Kapodistrian

Keywords: inguinal hernia, mesh, infection, prophylaxis, gentamycin

\section{A commentary on}

Hernia, Mesh, and Topical Antibiotics, Especially Gentamycin: Seeking the Evidence for the Perfect Outcome...

by Kulacoglou H. Front Surg (2014) 1:53. doi: 10.3389/fsurg.2014.00053

Konstantinos George Tsalis,

Aristotle University of

Thessaloniki, Greece

Reviewed by:

Apostolos Georgios Kamparoudis, Aristotle University of

Thessaloniki, Greece

Gabriel Sandblom

Karolinska Institute (KI), Sweden

Ulf Gunnarsson,

Umeå University, Sweden

${ }^{*}$ Correspondence:

Ekaterini Christina Tampaki

actampaki@yahoo.com

Specialty section:

This article was submitted to

Visceral Surgery,

a section of the journal

Frontiers in Surgery

Received: 05 April 2017 Accepted: 07 November 2017

Published: 27 November 2017

Citation:

Tampaki EC, Tampakis A, Kontzoglou K and Kouraklis G (2017) Commentary: Hernia, Mesh, and

Topical Antibiotics, Especially Gentamycin: Seeking the Evidence for the Perfect Outcome....

Front. Surg. 4:69.

doi: 10.3389/fsurg.2017.00069
It was a pleasure to go through the manuscript by Hacan Kulacoglou (1) published in Frontiers in Surgery, which focuses on topical antibiotic prophylaxis use especially gentamycin in clean surgeries such as in inguinal hernia mesh reconstructions, as he brings up excellent discussion topics.

Indisputably there are benefits in using antibiotics topically rather than orally or intravenously, reducing the chances of bacterial resistance and presumably the risk of having a surgical site infection (SSI), however leading to unwanted effects development, with the most common being contact dermatitis (2).

It has been suggested that gentamycin, topically or parenterally administered (1), is effective especially against Gram-negative bacteria; however, its use as empirical monotherapy or in combination with other antibiotics in clean surgeries has not been officially comparatively evaluated. Antibiotic choice, duration, dose, dosing interval, and first dose timing in contaminated but also in clean fields appear significant and would rather depend on the antibiotic's adverse effect profile, drug interactions, and the probability of bacterial resistance, especially given the emergence of bacterial resistance to third-generation cephalosporins, causing great concerns.

Although antibiotic prophylaxis is not mandatory in clean, elective operations, regular use of implants, accounting a $90 \%$ of inguinal hernia repairs, creates controversies (2). The European Hernia Society (3) does not suggest routine antibiotic prophylaxis. However, it is recommended where patient-related or procedure-related risks exist, as also Mazaki et al. indicated in a randomized controlled trial, showing that prophylaxis use proves to have effect on SSI prevention (4). Interestingly, mesh use in inguinal hernia reconstructive surgeries does not necessarily lead to greater wound infection risk (5). Latest data concerning wound infections regarding open mesh contrarily to non-mesh techniques used in inguinal hernia reconstructive surgeries suggest that deep infections surface rare and do not necessarily lead to mesh removal when mono- or multifilament mesh fabrics are applied along with drainage. Furthermore, the majority of RCTs are against using prophylaxis

Abbreviations: SSI, surgical site infection; SENIC, Study of the Efficacy of Nosocomial Infection Control; NNIS, National Nosocomial Infection Surveillance; EARS-NET, European Antimicrobial Resistance Surveillance Network; EHS, Environmental, Health, and Safety. 
in hernia repair procedures, whereas benefits in low-risk patients seem scarce $(6,7)$.

According to the Environmental, Health, and Safety guidelines, prophylaxis in clean operative procedures is not required. However, risk factors presented including the patient's age, immunosuppression status, co-morbidities, long operation duration, and drainage use are an exception (8). Further classification of the patients in low-risk and high-risk groups for SSIs seems mandatory. According to the most widely known risk indexes Study of the Efficacy of Nosocomial Infection Control and National Nosocomial Infection Surveillance evaluating the SSI rates, significant risk factors related to high SSI rates include abdominal operation processes, a more than 2-h procedure, wounds classified as dirty/infected or contaminated and patients being operated with more than three discharge diagnoses (9). Another significant issue underlined is the accurate and adequate estimation of SSI rates which can lead to significant bias and false results according to different definitions given concerning the SSIs, their time of occurrence, the patients follow-up and the study designs. The above moves the focus away from examining the most significant factors related to SSIs, which are the surgical microenvironment and the level of a country's health service (9). By all means, an SSI rate of above or below 5\% in many centers should not be objectively judged and implementations should be determined according to standard criteria.

Several surveys from England emphasize the surgeon's preference in using antibiotic prophylaxis also in low-risk patients regarding hernia repair procedures despite the lack of adequate clinical evidence (10). The first study on aminoglycoside resistance in Upper Egypt showed that implementation of newer aminoglycosides in terms of more resistant bacteria eradication could help in mixed infections, with aminoglycosides and b-lactams acting synergistically, whereas among the regimens tested, gentamicin and amoxicillin combination has proven the least productive. They also concluded that the high resistance rates to aminoglycosides could be reduced by imposing efficient infection control policies. Among different nations, extremely

\section{REFERENCES}

1. Kulacoglou H. Hernia, mesh, and topical antibiotics, especially gentamycin: seeking the evidence for the perfect outcome.... Front Surg (2014) 1:53. doi:10.3389/fsurg.2014.00053

2. Heal CF, Banks JL, Lepper PD, Kontopantelis E, van Driel ML. Topical antibiotics for preventing surgical site infection in wounds healing by primary intention. Cochrane Database Syst Rev (2016) 11:CD011426. doi:10.1002/14651858. CD011426.pub2

3. 18th annual hernia repair. Hernia (2017) 21(Suppl 1):1. doi:10.1007/ s10029-017-1571-5

4. Mazaki T, Mado K, Masuda H, Shiono M, Tochikura N, Kaburagi M. A randomized trial of antibiotic prophylaxis for the prevention of surgical site infection after open mesh-plug hernia repair. Am J Surg (2014) 207:476-84. doi:10.1016/j.amjsurg.2013.01.047

5. Falagas ME, Kasiakou SK. Mesh-related infections after hernia repair surgery. Clin Microbiol Infect (2005) 11(1):3-8. doi:10.1111/j.1469-0691.2004.01014.x

6. Tzovaras G, Delikoukos S, Christodoulides G, Spyridakis M, Mantzos F, Tepetes $\mathrm{K}$, et al. The role of antibiotic prophylaxis in elective tension-free mesh inguinal hernia repair: results of a single-centre prospective randomized trial. Int J Clin Pract (2007) 61:236-9. doi:10.1111/j.1742-1241.2006.00977.x high resistance to gentamicin (94.5\%) in Turkey versus (32.6\%) India was observed, whereas the most common resistant phenotype in Greece was that of kanamycin-neomycin (11), which may be attributed to deviations and variances in aminoglycoside treatment regimens. Resistance rates also rise varying widely between European countries. Reporting resistance rates to thirdgeneration cephalosporins reached up between 20 and 30\% in 2012 with a documented increase in aminoglycoside resistance rates (12).

The above highlights the vital importance of evaluating the surgical microenvironment and the level of a country's health service as the most significant factors related to SSI rates. When examining antibiotic prophylaxis in clean surgeries, issues such as bacterial resistance development should be determined after taking into consideration annual updates from the European Antimicrobial Resistance Surveillance Network and reports on health cost increase per country, as such changes in resistance are always indicative of valuable trends.

Worth mentioning is that increased incidences of adverse effects have been recorded when adding aminoglycosides to b-lactams versus b-lactam monotherapy (13). Fruitful implementation of infection control measures will reduce the problem of bacterial resistance decreasing the length of hospital stay, treatment costs, and mortality rates. Therefore, as there is no system to regularly monitor antibiotic resistance or the treatment efficacy in the community, providing data that would help guide empirical antibiotic therapy also in the case of clean surgeries, clinically applying empirical combination antibiotic regimens in clean surgeries is a matter of great importance and has to be examined with caution.

\section{AUTHOR CONTRIBUTIONS}

ECT conceived of the idea and wrote the manuscript. AT helped to draft the manuscript. KK and GK helped to revise the manuscript. All authors read and approved the final manuscript.

7. Othman I. Prospective randomized evaluation of prophylactic antibiotic usage in patients undergoing tension free inguinal hernioplasty. Hernia (2011) 15:309-13. doi:10.1007/s10029-011-0783-3

8. Simons MP, Aufenacker T, Bay-Nielsen M, Bouillot JL, Campanelli G, Conze J, et al. European Hernia Society guidelines on the treatment of inguinal hernia in adult patients. Hernia (2009) 13:343-403. doi:10.1007/s10029-009-0529-7

9. Ortega G, Rhee DS, Papandria DJ, Yang J, Ibrahim AM, Shore AD, et al. An evaluation of surgical site infections by wound classification system using the ACS-NSQIP. J Surgical Res (2012) 174:33-8. doi:10.1016/j.jss.2011.05.056

10. Aiken AM, Haddow JB, Symons NR, Kaptanis S, Katz-Summercorn AC, Debnath D, et al. Use of antibiotic prophylaxis in elective inguinal hernia repair in adults in London and south-east England: a cross-sectional survey. Hernia (2013) 17:657-64. doi:10.1007/s10029-013-1061-3

11. Gad GF, Mohamed HA, Ashour HM. Aminoglycoside resistance rates, phenotypes, and mechanisms of Gram-negative bacteria from infected patients in upper Egypt. PLoS One (2011) 6(2):e17224. doi:10.1371/journal. pone. 0017224

12. European Centre for Disease Prevention and Control. Antimicrobial Resistance Surveillance in Europe 2012. Annual report of the European Antimicrobial Resistance Surveillance Network (EARS-Net) (2014). 218 p. Available from: www.ecdc.europa.eu 
13. Bliziotis IA, Samonis G, Vardakas KZ, Chrysanthopoulou S, Falagas ME. Effect of aminoglycoside and beta-lactam combination therapy versus beta-lactam monotherapy on the emergence of antimicrobial resistance: a meta-analysis of randomized, controlled trials. Clin Infect Dis (2005) 41(2):149-58. doi: $10.1086 / 430912$

Conflict of Interest Statement: The authors declare that the research was conducted in the absence of any commercial or financial relationships that could be construed as a potential conflict of interest.
The reviewer $\mathrm{AK}$ and handling editor declared their shared affiliation, and the handling editor states that the process nevertheless met the standards of a fair and objective review.

Copyright (C) 2017 Tampaki, Tampakis, Kontzoglou and Kouraklis. This is an openaccess article distributed under the terms of the Creative Commons Attribution License (CC BY). The use, distribution or reproduction in other forums is permitted, provided the original author(s) or licensor are credited and that the original publication in this journal is cited, in accordance with accepted academic practice. No use, distribution or reproduction is permitted which does not comply with these terms. 